\title{
Putting agricultural equipment and digital technologies at the cutting edge of agroecology
}

\author{
Véronique Bellon Maurel ${ }^{1, *}$ and Christian Huyghe ${ }^{2}$ \\ ${ }^{1}$ Irstea, \#DigitAg Convergence Laboratory, 1 rue Pierre-Gilles-de-Gennes, 92761 Antony cedex, France \\ 2 INRA, 147 rue de l'Université, 75338 Paris cedex 07, France
}

Received 21 May 2017 - Accepted 15 May 2017

\begin{abstract}
The agro-ecological transition is an ambitious challenge. It can be met by implementing the fundamentals of agroecology (use of biodiversity, integration of agriculture in landscapes, closure of flow loops) in the context of a broad and renewed offer of technologies: agro-equipment, biotechnology, digital technologies... This article explores the role that agro-equipment and digital services can play in this transition. These technologies contribute through various levers to the agro-ecological transition: by improving farming efficiency (more service rendered for the same environmental impact), by precision farming (adaptation of the operations to the needs of the plant or the animal based on a monitoringdiagnosis-recommendation cycle) and by the development of specialized machinery helping the farmer to achieve "flow loop-closing" (at the plot level, by maintaining the soil quality, or at the farm level, with the recycling of organic effluents) or to take advantage of biodiversity (e.g., with agro-equipment adapted to mixed crops). The technological bricks that are requested and for which advances are expected are: sensors (to measure plant or animal needs) and associated digital technologies (information transfer, data processing), precision technologies for input application, robotics, specialized machines to manage soil cover and weeds, or for agroforestry. The brakes and engines for innovation in agro-equipment are studied. The brakes are the generally small structure of the farm manufacturing companies, the deficit of the demand from farmers and the complexity - either real or perceived - of these equipments. To encourage innovation, several levers are to be used: involving users in the design of agro-equipments, creating financial incentives for innovative equipment purchase, and training end-users, prescribers and dealers to the high potential of these new technologies. In conclusion, putting agro-equipment and digital technology at the service of agroecology is not a straightforward route, but it is above all a real opportunity to produce better, technically and organizationally, with the emergence of new solidarities (sharing of data and knowledge). This is why it is absurd, as it is sometimes read, to oppose agroecology and technology. Agroecology is a set of practices to be built, while agro-equipment and digital technologies are a set of resources to be mobilized, with others, to achieve the objectives of sustainable agricultural production.
\end{abstract}

Keywords: agricultural equipment / digital technologies / agroecology / optimization / farm machinery / digital agriculture / IoT / precision agriculture

Résumé - L'agroéquipement et les technologies numériques, possibles leviers de l'agroécologie?
La transition agroécologique est un challenge ambitieux qui pourra être relevé en mettant en œuvre les
fondamentaux de l'agroécologie (utilisation de la biodiversité, insertion de l'agriculture dans les paysages,
bouclage des flux) dans le cadre d'une offre large et renouvelée de technologies: agroéquipements,
biotechnologies, numérique... Cet article étudie le rôle que peuvent jouer les agroéquipements et services
numériques dans cette transition. Ces technologies contribuent via divers leviers à la transition
agroécologique, via l'amélioration de l'efficacité (plus de service rendu pour le même impact
environnemental), l'agriculture de précision (adaptation aux besoins de la plante dans un cycle de type
"observation - diagnostic - préconisation - application ») et le développement de machines spéciales
pour implémenter le bouclage des flux (au niveau de la parcelle, en maintenant la qualité des sols, ou au

* Corresponding author: veronique.bellon@irstea.fr 
niveau de l'exploitation, avec le recyclage des effluents organiques) ou pour tirer parti de la biodiversité (agroéquipements adaptés aux cultures mixtes par exemple). Les briques technologiques qui sont sollicitées et pour lesquelles des avancées sont attendues sont : les capteurs (pour mesurer l'expression des besoins des plantes ou des animaux) et le numérique (transfert d'information, traitement de données), les technologies de précision pour l'application d'intrants, la robotique, les machines spéciales pour gérer la couverture du sol ou pour l'agroforesterie. Les freins et les moteurs pour l'innovation en agroéquipements sont étudiés. Côté freins, ont été identifiés la petite structure des agroéquipementiers, le déficit de la demande et la complexité réelle ou perçue de ces équipements. Pour favoriser l'innovation, plusieurs leviers sont actionnables: associer les utilisateurs (agriculteurs, entrepreneurs) à la conception des agroéquipements, créer des incitations financières à l'achat d'équipements innovants, et enfin former, non seulement les utilisateurs finaux mais aussi les prescripteurs et concessionnaires au potentiel de ces nouvelles technologies. En conclusion, mettre les agroéquipements et le numérique au service de l'agroécologie est une voie peu banale, mais qui est aussi et surtout une réelle opportunité de produire autrement, d'un point de vue technique et organisationnel, avec l'émergence de nouvelles solidarités (partage des données, partage des savoirs). C'est pourquoi il est absurde, comme on le lit parfois, d'opposer ces deux entités, l'agroécologie - bouquet de pratiques à construire - et l'agroéquipement et le numérique - bouquet de ressources à mobiliser, avec d'autres, pour atteindre les objectifs d'une production agricole durable.

Mots clés : agro-équipement / numérique / agroécologie / optimisation / machinisme / IoT / agriculture numérique

Agroecology defines a new paradigm to design farming systems that are more environment-friendly and more efficient in their use of resources. In 2013, at the Paris "Agroecology and Research" symposium", the three main leverages for agroecology were identified. These are the support and creation of biodiversity and functional diversity, the integration of agriculture and landscape and the control of the more significant biogeochemical substances in a closed loop system.

This new approach, which marks a turning point in agricultural production methods, builds on practices that have been developed over several decades, such as optimizing the efficiency of agricultural inputs in plant and animal production, replacing synthetic inputs and limiting the flow of pollutants in the environment.

The key role of farm machinery in this transition was also highlighted at the Paris conference. This paper examines the major issues that arise in the relationship between agricultural equipment and the agroecology challenge: how could farm machinery play a role in the transition towards agroecology? What technologies should be developed? And what are the obstacles and drivers for the development of these technologies?

\section{Three areas of innovation in agricultural equipment for an agroecological future}

Starting with the fact that the objectives of agroecology are to increase economic, environmental and also social performances, we can identify three areas of innovation where agricultural equipment is able to contribute through introduction of both new technologies and new practices.

\footnotetext{
${ }^{1}$ The "Agro-ecology and research" colloquium was held in October 2013 and was organised by INRA with the support of the Ministry of Agriculture and in partnership with the Agreenium and Allenvi research alliances.
}

\subsection{Increasing efficiency}

As a general rule, all improvements in the efficiency of agricultural equipment contribute to the reduction of:

- consumption of fossil fuels, water and other agricultural inputs;

- physical impacts on soils (compaction, disintegration, erosion, etc.);

- release of contaminants in environmental compartments (water, soil, air).

All this is deemed beneficial in that it reduces environmental impacts while increasing efficiency, thereby improving economic performance.

\subsection{Use of precision technologies}

Precision agriculture and precision livestock farming adjust input doses to match the needs of crops or animals. Inputs to a heterogeneous population are regulated according to the needs of each individual (within a plot, group of animals, etc.) while practices are adapted to suit local environmental conditions (soil condition and depth, wind, etc.).

Precision agriculture and precision livestock farming use bundle of new information and communication technologies (ICT) in a "sensor-actuator" control system loop comprising: - observation, from sensors, satellite data or manual input;

- diagnosis (of the status of crops or animals), using modelling;

- recommendation, using knowledge-based models;

- action, using automated input systems.

\subsection{Developing specialised farm machinery and new practices}

Specialized agricultural equipment plays a particularly important role in increasing the functional diversification of 
agricultural systems and helping to recycle elements in a closed-loop system.

\subsubsection{Increasing the functional diversity of agrosystems}

To increase the functional diversity of agrosystems, new cultural ways are created by introducing additional varieties, mixtures of species and / or additional species as commercial or intermediate crops. In addition, practices such as undercover seeding, in-mulch seeding or interplanting, agroforestry and in-field grass strips (e.g., between vines, fruit trees or grain crops) can contribute to diversification. Extended rotations and use of intermediate crops call for the adaptation of seeding techniques to suit cover-plant seeds and to manage soil incorporation of crop residues. Landscape design must also be modified and particular attention must be paid to the management of field margins and agroecological infrastructures such as hedges, buffer strips or wetland habitats. All these new practices require special farm equipment.

\subsubsection{Using biogeochemical substances in a closed-loop system}

Agroecology closes the loop of biogeochemical flows both by facilitating natural processes and by intensifying recycling on the farm.

To enable natural biogeochemical recycling, soil protection is essential. Particular attention must be paid to the conditions under which tillage, sowing and soil maintenance operations are carried out to reduce the risk of soil compaction (because of heavy machinery or inappropriate pneumatic equipment). It is necessary to limit the intensity of tillage, to till only where and when necessary, and to aim for continuous soil cover for improving water infiltration and storage into soil.

These different practices require soil cultivation tools that preserve the presence of a mulch on the surface or use minimum tillage (strip-till) as well as seeders adapted to direct seeding, and seeding into dead or living mulch (i.e. an existing crop).

To intensify the recycling of organic matter, effluent and organic waste is used as a soil conditioner following composting or anaerobic digestion. Good manure management includes covering of manure pits, separation of liquid and solid phases and subsequent application of the manure by localized spreading or by incorporation in order to limit gaseous emissions.

In addition to specialised farm machinery, such recycling requires integrated management of sources of biomaterials at a local level and a shared use of processing equipment (anaerobic digesters) in order to minimise environmental and economic impact of the transport of materials.

\section{How does farm machinery support agroecology?}

The contribution made by farm machinery to agroecology can be divided into four main categories:

- digital technologies for data acquisition and processing. Knowledge of the needs of crops or animals is essential and this must be modelled to enable appropriate diagnosis and recommendations to be made;
- precision technologies make it possible to tailor interventions to each individual (or group of similar individuals);

- autonomous technologies allow agile interventions with minimum impact;

- specific technologies support new cultivation practices.

\subsection{Data acquisition and data processing technologies}

\subsubsection{Data entry and transmission}

These technologies make use of sensors which can be installed in different locations: fixed (on the ground or onto plants to be measured) singly or in a network, carried by operators (portable sensors), attached to or implanted in the animals, or embedded in farm machinery (tractors and tools) or aerial vehicles (drones, planes, satellites). The spatial and temporal resolution of the measurement largely depends on which of these modes of implementation is used. Sensors can:

- record the state or the behaviour of an organism (plant, animal), either in real time or as historical or "deferred" data;

- characterize properties of local environment, including physical, chemical and biological soil properties, heterogeneity within plots, spatial environment (field margins, neighboring plots, agroecological infrastructures), temporal environment (previous crops, intercrops, residues, etc.), herd environment, either outdoors or in livestock buildings (temperature, air flow, gas concentrations, etc.).

The objective of such recording and analysis is to increase knowledge of the environment in order to improve understanding of the behavior of crops or animals and, ultimately, to optimize their interaction with the environment.

The list of sensor-types is very broad: soil moisture probes; $\mathrm{pH}$ sensors; plant deformation sensors to detect plant water stress; temperature sensors and accelerometers to provide data on animal health; and various optical sensors (UV-visible cameras, hyper-spectral cameras, infrared sensors, nearinfrared spectrometers, lidar, etc.). Weather data are also essential to prediction models and improved weather forecasts would significantly increase the added value, interest and eventual adoption of precision agriculture.

Ultimately, "connected objects" will become a standard part of agriculture. Connected weather stations, linked to agricultural machinery and sensor networks on the farm, are a first example of connected objects.

Smartphones can implement dedicated applications that capture operational data, provide advice to the farmer, recognize weeds, carry out specific measurements (of colour, shape, density, etc.) and access reference databases. When no sensor is available to measure a given variable (such as disease or attacks by pests), the relevant information can be entered manually on a terminal that transmits the data in a formatted and usable form. Smartphones are increasingly used for this purpose, bringing together various functions (such as measurement, geolocalisation, connection and display) useful for professional applications. Because they are easy to use, they make it possible to collect networked observations that can be shared across a particular agricultural area. 
Data is then transferred via high-speed systems provided by mobile or, if collected at low frequency, by low-throughput operators (SiFox, LoRa, etc.). For storage and exchange, data clouds, although not without security issues, are often portrayed as revolutionary. Database interoperability is a further concern since it is dependent on the normalisation and standardisation of exchange protocols and data repositories.

\subsubsection{Reaping the benefits of data processing: smart data and big data}

Data generated by sensors or operators are converted into indicators, advice, recommendations and automated instructions using either conventional statistical processing methods or methods derived from artificial intelligence, also called "deep learning", thereby becoming "smart data".

As in other economic sectors, increasing amounts of data are generated in agriculture, resulting in what has become known as agricultural "big data". Big data is characterized by the three "V"s: Volume, Variety and Velocity. Variety is the most significant property of agricultural data since the data are very diverse, non-standardised and derived from a range of sources involving different actors. Volume of information can also be significant, in the case of phenotyping data or satellite images for example, and this requires new methods of data mining. Based on these vast quantities of data, new knowledge models can be created. The success of such innovative approaches to knowledge creation depends on access to these heterogeneous data and particular attention must be paid to the question of data ownership and governance. There are a number of initiatives in France and elsewhere that facilitate access to data; for example, the Agrimetrics Data Hub in the United Kingdom, API-AGRO developed by ACTA, or the AgGate data portal project (Bournigal, 2016) and \#DigitAg, the digital agriculture convergence Lab (www.hdigitag.fr).

\subsection{Precision technologies}

With the benefit of precision technologies, human intervention can be limited to ensuring that the needs of plants or animals are met, making it possible to reduce inputs.

\subsubsection{Spraying}

New types of sprayer offer ways to move closer to the goals of agroecology: dosages may be adjusted according to leaf area or volume (measured by radar, optical sensors or Lidar) and spray could selectively target areas affected by disease. These sprayers can be designed to restrict drift and thus maximize input efficiency. In the case of vines, the joint technological unit EcotechViti ${ }^{2}$ deserves mention for its work on spray quality assessment (evaluating foliar application performance and losses in the ground or air).

\footnotetext{
${ }^{2}$ UMT EcotechViti is a mixed technological unit working to reduce the reliance of winegrowers on pesticides.
}

\subsubsection{Spreading livestock manure}

Organic waste products are a source of fertilizers and their use in agricultural production is essential to closing geochemical cycles, a core objective for agroecology. Improving quality of organic fertilizer spreading is a major challenge, as such fertilizers are characterized by the great diversity of their shape (liquid to solid) and chemical composition. French professionals, working to a European standard, are developing an "Ecospreader" label that is managed by Axema, the French Agricultural Equipment Manufacturers Union.

\subsubsection{Precision irrigation}

Well-managed irrigation controls water use and energy consumption, thereby improving profits. Precision irrigation is based on a new generation of models capable of estimating water needs of plants. Recommendations are made based on data collected by sensors (such as neutron probes, dielectric and capacitive probes and remote sensing and monitoring devices) which then feed a diagnosis and hydraulic assessment. Precision irrigation is carried out using pivot or drip systems.

\subsubsection{Self-guiding and assisted guidance equipment}

Precision technologies are classically used in conjunction with geolocalisation, which provides a reference for observations and recommendations. Real time kinematics (RTK) GPS guidance is promising as it has very high precision levels, down to about $30 \mathrm{~mm}$. RTK antennas are generally jointlyowned infrastructures as they are expensive, but they can cover a radius of $10 \mathrm{~km}$.

\subsection{Autonomous technologies}

Autonomous technologies are less heavy and cumbersome and consequently have less impact than conventional technologies, earning them a place in the agroecological toolkit.

\subsubsection{Robots}

With robots, repetitive or dangerous tasks are executed autonomously. Machines adapt their actions to variations in local conditions. There are currently three main areas of use for commercial robots:

- after a slow start, robotic milking machines are rapidly developing in France: $45 \%$ of dairy production facilities in Brittany now use robotic milking machines. These reduce the stress put upon farmers and enable them to gather information on animal health and on the milk collected through integral flow and quality sensors.

- automatic feeding systems are programmed to meet animals' needs. Mobile animal feeding robots prepare and distribute fresh fodder (silage, hay) throughout the day, increasing the animals' appetites and hence productivity.

- outdoor weeding machines are in the development phase; they look for, identify and then destroy weeds by means of localised application of herbicides or physical, mechanical or thermal treatment. At the time of writing, Naïo Technologies ${ }^{3}$ has

\footnotetext{
${ }^{3}$ Naïo Technologies supplies robots for winegrowers.http://www. naio-technologies.com.
} 
distributed several tens of mobile devices for mechanical weeding, mainly in vegetable production systems and vineyards.

\subsubsection{Assisted guidance}

The availability of assisted guidance in agricultural machinery has led to both developing new technologies and revisiting old ones. Guidance is achieved by using optical or laser-type proximity sensors. Laser-guided hoeing machines, equipped with a wide variety of teeth to suit the crop to be weeded, are designed to pass very close to the seedlings without damaging them. This technology is becoming increasingly precise - e.g., accurate to $10 \mathrm{~mm}-$ and has the capacity to be rolled out in the future for use with closelyspaced crops such as cereals. Laser guidance also makes it possible to optimize the alignment of larger machines such as vine sprayers equipped with spray recovery panels.

In future, there may be increased interest in automaticallyguided "controlled traffic farming" (CTF) machines in the wake of expanding development of agroforestry. CTF machines have a very precise trajectory, avoiding the soil compaction that results from the repeated passages of machinery. CTF is possible only if the widths of all tools used throughout the crop cycle are compatible.

\subsection{Specific technologies supporting new cultivation practices}

In order to encourage biotic interactions in crops, common practices, such as multiple crop associations, can be updated and adopted across larger areas thanks to developments in farm machinery. Examples are given below.

\subsubsection{New machines and equipment for continuous soil cover}

Drawbacks of tilling are born from the use of heavy and powerful equipments which are both expensive and leading to destruction of soil structure.

Simplified cultivation techniques that protect soils can offer an alternative. These preserve mulches and groundcovers that outcompete weeds, limit evaporation and reduce the risk of erosion between crops. In order to benefit from this mulch, it is necessary to sow within the mulch, ensuring that seeds are in contact with the soil for rapid growth. Strip tilling reduces tilling to a narrow strip in which seeds are sown. For row crops, geolocalisation has made it possible to sow in staggered rows. Staggered-row sowing speeds up cover development and favours crop development over that of weeds. The particular challenge these methods present for the development of farm machinery is that they require the effective and precise positioning of seeds to guarantee implantation and growth.

Soil structure can also be preserved by reducing tyre pressures, especially in the case of large tyres: these can be adjusted using automated inflating systems that alter the pressure in response to the bearing capacity of different soils. This has the advantage of both limiting soil compaction and enhancing ground adhesion, enabling the farmer to work in a wide range of weather conditions.

\subsubsection{Mechanical weed management}

Weed management is a major issue in agriculture. First, weeds are in competition with crops, thereby reducing productivity; second, weeds that are not eradicated leave seeds in the soil, leading to future problems.

One mechanical method of managing weeds is "weed harrowing". This combines weeding in rows and harrowing between rows. It is also possible to combine targeted sowing and harrowing based on precise geolocalisation.

A second option is to manage weed life-cycles. As weed inflorescences are often located above the crops, they can be cut early with a header. This technique, already used in organic farming, helps to reduce the weed seed bank and can be adapted to agroecology by developing new equipments for multiple crops. Australian engineers have gone a step further by developing a combine that incorporates a weed seed recovery system (Harvest Weed Seed Control) (Walsh and Powles, 2014).

\subsubsection{Mixed cropping and agroforestry}

Mixing different crops or mixing crops with tree cover improves management of biodiversity, but specifically designed equipment is needed for these new practices and systems. For mixed crops, such as wheat/pea mixtures, the different species are harvested simultaneously and must therefore be separated by mechanical or optical sorters.

For agroforestry, machinery is needed to set and maintain the tree cover without damaging crops. For instance, hedges can be managed using new equipment that also collects the trimmings which, along with slash from clear felling, can be turned into pellets or chippings.

\subsubsection{Efficient livestock and closed-loop systems}

A wide range of equipment to help the different stages of fodder production - mowing, drying and conditioning (making and baling silage and/or hay, etc.) - is still under development. New equipment is being developed to reduce drying duration and losses, to increase the nutritional value of fodder and also to allow better working conditions. In-bale air injection as well as "barn drying" either in bulk, in boxes, or with round or square bales are fast-developing practices.

Farmers also seek to increase economic and environmental efficiency of barns through temperature monitoring and gas scrubbing, which captures ammonia before air extraction. This process requires excellent management of data collected by sensors along with detailed knowledge of the way the barn is used.

Last, farms can be managed as closed-loop systems, provided that livestock is appropriately linked to crop production. In that case, the right machinery is essential to the efficient management of farm effluents, e.g., through methane production and/or manure spreading.

\section{How to encourage the use of farm machinery as part of the agroecology transition?}

It is crucial to identify barriers and drivers for the innovation and adoption of high-tech farm machinery, given its role as a lever for agroecology transition. 


\subsection{Barriers}

A first obstacle lies in the size of farm machinery companies: most are PMEs with limited research capacity. Another major obstacle is to be found in the lack of interaction between farm machinery designers, on the one hand, and designers of new cultivation and breeding systems, on the other: a joint working between them is urgently needed.

But the main impediment may lie in the lack of demand from farmers. Because specialised farm machinery is a niche market, it is expensive, bringing high investment costs. Solutions include sharing equipment between farmers, outsourcing farm works' services, extending the useful life of machinery, putting in place tax incentives or a regulatory framework to support the acquisition of specialised farm machinery. A move towards mass production, with its economies of scale, is another way to be encouraged using public incentives to cut costs and target wider markets.

Last, users may be deterred from using new technologies by their complexity. Here, there is a compelling need for further work on ergonomics and for training to be organised.

Regarding digital development in farm machinery, software packages are generally available in this and other sectors. Significant research and development effort will however be needed to adapt such technologies to the particular requirements of farm machinery that will support the transition to agroecology.

\subsection{Incentives to use new agricultural equipment}

Three main levers can be identified that would encourage adoption of new agricultural equipment by farmers.

The first of these is to boost user participation. The "learning by doing" approach invites farmers to use equipment and give feedback in a collaborative design venture (the "design thinking approach"). Farmer networks have to be created to encourage knowledge transfer. Networking is made possible, for instance, by the installation of shared equipment (such as RTK transmission towers), by consultation on agricultural equipment (e.g., as seen for barn management) or by developing collective actions to encourage the adoption of new equipment on a larger scale. In this, farm machinery cooperatives and agricultural contractors have a major role to play.

Financial leverage is also possible. For instance, to encourage eco-friendly practices, the "Future of Agriculture and Forests" bill was passed in France in September 2014 which included an experimental period of certificates achieving savings in the use of phytosanitary products. This design is relevant to equipments. Those awarded such pesticide saving certificates then qualify for grants. Similar incentives targeting other types of inputs, such as nitrogen, could be introduced. Here, it is essential to establish the level of benefits derived from such incentives by the acquisition, whether individual or collective, of farm machinery that optimises input applied doses.

In addition to tax incentives, it would certainly be justifiable to direct targeted public financial subsidies towards farm machinery intended for agroecology. This would both reduce environmental impacts and support a new emerging industry.
Last, significant leverage can be achieved through training. Farmers, farm machinery retailers and agricultural advisors must all be trained to use new technologies and machines. Specific training sessions on ICT, new technologies and farm machinery must be fully embedded in the curriculum of schools and colleges that specialise in agriculture. Students in engineering (electronics, computer sciences, mechanics, etc.) should be more clearly informed about the openings and potential for career development offered by farm machinery companies, which are short of trained workers.

\section{Conclusion: down with clichés!}

We can conclude with three critical assertions. First, the adoption of new technology is a critical point, to be taken into account as soon as possible. Second, new technologies open up opportunities for collective working and solidarity. And, last, a misconception about the relationship between agroecology and machinery needs to be dispelled.

\subsection{Adoption of agricultural equipment: a critical point}

Farmers' adoption of these new technologies, particularly digital technologies, is crucial. In order to analyse the conditions that encourage farmers to adopt these technologies we must focus on the triggers for their decisions. Numerous factors influence decision-making: input costs; the effects of product prices on incomes; farmers' attitudes towards risk management; their education and training; how easy it is to access information, etc. When choosing agricultural equipment for agro-ecological practices, the main factors to be considered are:

- the annual cost of the equipment. This depends on parameters such as the cost of investment, tax regulations, tax exemptions, depreciation, funding possibilities and existing debt, as well as possibilities for equipment sharing;

- the level of labour productivity (measuring the ratio between production volume and time needed to achieve it) as well as quality of work (linked to working conditions);

- the farmer's ability to use the machines and equipment in different conditions (humidity, wind, soil bearing capacity, etc.);

- the alleviation of arduous working conditions;

- the access to decision-making and information-management systems to reduce investment risk;

- the farm financial situation;

- the opportunities for collective acquisition of equipment to reduce capital outlay and encourage adoption of new techniques and practices.

Producers of new agricultural equipment will have to address all these issues in order to increase market share. Last, but not least, the preparedness of farmers to adopt new agricultural equipment depends on the will and desire to embrace modernity and act to promote high-tech agriculture.

\subsection{Agricultural equipment and digital technologies: towards a greater solidarity}

There is no way of knowing the full potential of digital technologies in agriculture, as this future is for a large extent still to be built. Currently, they are commonly used to give 
access to knowledge and information, for example, to provide instant solutions to practical problems. But, digital technologies may provide the opportunity for new ties within the farming community and along the value chains. When used on a shared basis, farm machinery can become a mediation tool that benefits collective skill development. What is more, data collection and sharing provide farmers with the chance to develop their networking: sharing data is easy and cheap and it leads to better management on the farm (for example, by sharing information on diseases, weather, and so on) and within a community (by sharing information on practices).

Sharing data makes it possible to further develop good practices as collective knowledge increases. Metcalfe's law highlights that the more users there are in a network the more value this network will have. In this knowledge-sharing model, networks allow relationships between learners and teachers to be modified. Both direct and indirect network externalities must be taken into account. Creative applications to increase knowledge and information sharing have yet to be developed.

\subsection{Eventually, farm machinery and agroecology are inextricably linked}

This article has repeatedly demonstrated that farm machinery and digital technologies must be seen as key elements of agroecology transition. This also dispels the myth that agroecology and digital technologies are incompatible because the former would be based on "natural" processes only, while the latter would be suited only to intensive farming. This perception is entirely without foundation, since the more we seek to adapt farming to its environment, the more we need data, observations and diagnosis to better understand crop needs. The future will lie in the shared construction of agroecological practices and systems, and of the associated farm machinery/digital technologies. It is for us to be creative in this field!

Acknowledgement. The authors acknowledge the contribution of colleagues from INRA (from H. Guyomard, J.L. Peyraud, J.F Soussana, C. Gascuel, G. Richard, M. Voltz, M. Cerf, X. Reboud, T. Caquet), Irstea ( R. Lenain, J.P. Chanet, M. Berducat, O. Naud) \& Montpellier Supagro (B. Tisseyre).

\section{References}

Bournigal JM. 2016. AgGate - Portail de données pour l'innovation en agriculture. Ministère de l'agriculture, de l'agroalimentaire et de la forêt. 138 pages. Date de remise : January 2017. Disponible sur : http://www.ladocumentationfrancaise.fr/rapports-publics/ 174000039/index.shtml (Last consult: 2017/06/07).

Walsh MJ, Powles SB. 2014. High seed retention at maturity of annual weeds infesting crop fields highlights the potential for harvest weed seed control. Weed Technol 28 (3): 486-493.

Cite this article as: Bellon Maurel V, Huyghe C. 2017. Putting agricultural equipment and digital technologies at the cutting edge of agroecology. OCL 24(3): D307. 